\title{
Lack of effect of intravenous azathioprine on time to respond for steroid treated Crohn's disease
}

Sandborn WJ, Tremaine WJ, Wolf DC, et al. Lack of effect of intravenous administration on time to respond to azathioprine for steroid-treated Crohn's disease. Gastroenterology 1999;117:527-35.

\section{Aim}

To assess whether intravenous azathioprine decreases the time to achieve remission in patients with steroid treated Crohn's disease who are starting oral azathioprine therapy.

\section{Background}

Azathioprine is effective in preventing relapses of Crohn's disease although its therapeutic effect can be slow to develop. An intravenous infusion may decrease the time needed for oral therapy to become effective.

\section{Methodology}

Patients were those with Crohn's disease with a CDAI of $150-450$ points and receiving $\geqslant 20 \mathrm{mg}$ prednisolone/day for $\geqslant 4$ weeks. The study design was a multicentre, randomised, double blind, placebo controlled trial of either an infusion of intravenous azathioprine of $40 \mathrm{mg} / \mathrm{kg}$ over 36 hours or a placebo infusion. Following infusion, both groups received an oral dose of azathioprine $2 \mathrm{mg} / \mathrm{kg} / \mathrm{day}$. The primary outcome measures were complete remission (CDAI $<150$ ) and total steroid withdrawal by eight weeks.

\section{Results}

Fifty one patients received intravenous azathioprine of which $32(63 \%)$ completed the 16 weeks of treatment. Forty five received placebo infusion of which 26 (58\%) completed the study. After eight weeks the remission rate was $25 \%$ in the treatment group and $24 \%$ in the placebo arm $(\mathrm{p}=0.906)$. Clinical remission (CDAI $<150$ ), clinical improvement (CDAI $<150$ or total steroid withdrawal), and clinical improvement (decrease in baseline CDAI >70) were similar in both groups.

\section{Conclusions}

A loading dose of intravenous azathioprine does not decrease the time to response in patients with steroid treated Crohn's disease starting oral azathioprine therapy.

\section{Comment}

6-Mercaptopurine and azathioprine are established treatments for Crohn's disease, both for maintenance ${ }^{1}$ and induction of remission. ${ }^{2}$ They are the agents of choice for steroid dependant disease. Their use in Crohn's disease is limited in two ways. Firstly, potentially serious dose dependant and idiosyncratic hypersensitivity side effects occur in a significant minority of patients treated.
Secondly, the clinical effect has been said to have a prolonged time to onset with response rates only significantly increasing after 17 weeks of therapy, ${ }^{2}$ limiting usefulness in refractory active disease. Pharmacokinetic studies have suggested that the active metabolites of these drugs, the 6-thioguanine nucleotides (6TGN), have a long half life in red blood cells and slowly accumulate in tissues, requiring prolonged treatment to achieve steady state levels. ${ }^{3}$

Sandborn and colleagues have carefully addressed whether an intravenous loading dose of azathioprine would reduce the time to respond in patients with active Crohn's disease treated with steroids. An earlier open label study had raised this possibility. ${ }^{4}$ The primary outcome was complete remission, defined as a Crohn's disease activity index (CDAI) score $<150$ and steroid withdrawal at week 8. There was no difference between the two groups and other measures of response, including quality of life scores.

Despite the negative results of this study it does make other important clinical observations. The median time to clinical remission (CDAI <150) was 28 days in both groups and complete remission rates did not increase after eight weeks. This suggests a more rapid clinical effect than previously reported. ${ }^{2}$ In accordance with this, both groups achieved steady state 6 TGN levels by week 2 . Intravenous loading with azathioprine did not reduce the time to achieve steady state levels of $6 \mathrm{TGN}$, supporting previous data. ${ }^{5}$ However, with the low intravenous dose used and the extensive first pass metabolism, this might have been expected.

In both groups, the response rate was lower than expected (31\% intravenous group; $27 \%$ oral azathioprine) but this is difficult to interpret without a control group who did not receive oral azathioprine. It is possible that the low oral dose $(2 \mathrm{mg} / \mathrm{kg}$ ) and the limited follow up (16 weeks) contributed to this low rate. In addition, patients with low and intermediate thiopurine s-methyltransferase activity were excluded, accounting for $10 \%$ of patients and potentially those most likely to respond. This may also account for the lack of association between higher levels of 6TGN and the rate of complete remission observed in other studies. ${ }^{6}$

This study demonstrates that an intravenous loading dose of azathioprine, although safe, is ineffective in reducing time to response in active Crohn's disease. As this is not common clinical practice the results will not significantly alter current management. However, the response time to azathioprine is shorter than previously suggested, as is the time to steady state erythrocyte 6TGN levels. This illustrates the need for the continued clinical evaluation of these useful drugs in the treatment of Crohn's disease. Much remains to be learned about the relationship between all aspects of its pharmacology and its clinical efficacy, including dose response and pharmacogenetics. ${ }^{7}$

M J CARTER ALAN J LOBO Gastroenterology and Liver Unit, Royal Hallamshire Hospital, Sheffield S10 2fF, UK m.j.carter@shef.ac.uk alan.lobo@csuh.nhs.uk 
1 Pearson DC, May GR, Fick GH, et al. Azathioprine and 6-mercaptopurine in Crohn's disease: a meta-analysis. Ann Intern Med 1995;122:132-42.

2 Sandborn W, Sutherland L, Pearson D, et al. Azathioprine or 6-mercaptopurine for inducing remission of Crohn's disease (Cochrane Review). In: The Cochrane Library, Issue 1. Oxford: Update Software, 1999.

3 Lennard L, Lilleyman JS. Variable 6-mercaptopurine metabolism and treatment outcome in childhood lymphoblastic leukaemia. 7 Clin Oncol 1989;7:1816-23.

4 Sandborn WJ, Van Os EC, Zins BJ, et al. An intravenous loading dose of azathioprine decreases the time to response in patients with Crohn's disease. Gastroenterology 1995;109:1808-17.

5 Lennard L. The clinical pharmacology of 6-mercaptopurine. Eur 7 Clin Pharm 1992;43:329-39.

6 Dubinsky MC, Lamothe S, Yang HY, et al. Pharmacogenomics and metabolite measurement for 6-mercaptopurine therapy in inflammatory bowel disease. Gastroenterology 2000;118:705-13.

7 Yates CR, Krynetski EY, Loennechen T, et al. Molecular diagnosis of thiopurine s-methyltransferase deficiency: Genetic basis for azathioprine and mercaptopurine intolerance. Ann Intern Med 1997;126:608-14. 